\title{
THE INFLUENCE OF BIOPHYSICAL FACTORS ON PRODUCTIVITY AND BIOCHEMICAL COMPOSITION OF THE BLOOD OF SHEEPS
}

\author{
Larisa SKORYKH, All-Russian Research Institute of Sheep and Goat Breeding, Address: Stavropol, 15 Zootechnicheskiy Ln, Russia, \\ smu.sniizhk@yandex.ru \\ Vitaly GRINCHENKO Stavropol State Agrarian University, Address: Stavropol, 12 Zootechnicheskiy Ln, Russia, \\ grinchen_ko@mail.ru (corresponding author) \\ Michael AFANASYEV Stavropol State Agrarian University, Address: Stavropol, 12 Zootechnicheskiy Ln, Russia, \\ $\underline{\text { ssau_phisics@mail.ru }}$ \\ Nina KONIK Saratov State Agrarian University, Address: Saratov, 1 Theater Square, Russia, koniknv@ mail.ru
}

\begin{abstract}
As the livestock industry, sheep breeding takes the third place in the world, this is one of the most extensive types of agriculture. Currently, the main attention in the sheep breeding is directed to increasing in meat productivity and improving the quality of products. The important technique that contributes to the increase and improvement of the quality of livestock production is the use of laser radiation. The article presents the results of research directed to studying of influence of low-intensity laser radiation on the organism of young sheep. The area of impact of laser radiation on the animal organism is defined. The positive influence of laser radiation on the growth and development of young sheep and their immune reactivity is established. The revealed regularity is confirmed by the bigger size of the live weight, increased energy of growth in all studied periods of ontogenetic development, the more developed factors of natural protection at the experimental animals. The effectiveness of the directed impact of laser puncture on the organism of young sheep has been proved to improve meat productivity and resistance. The developed method of laser puncture can be used to increase the meat productivity, safety and resistance of young sheep.
\end{abstract}

Keywords: animal husbandry, laser puncture, productivity, resistance, sheep breeding.

\section{INTRODUCTION}

Sheep breeding is an important branch of the world's productive livestock. Currently, the main attention in the sheep breeding is directed to increasing in meat productivity and improving the quality of products. However, more attention is paid to the issue of healthy nutrition, which implies the use of environmentally safe foods, especially meat, as part of the daily ration. Therefore, the problem of growing healthy, viable animals, increasing their productivity and obtaining high-quality environmentally friendly products acquires particular urgency. One of the factors that can influence the formation of animal productivity, improving the quality of livestock production is the impact on the acupuncture points of animals with a laser beam (Nikitenko et al., 2016).

A certain interest in livestock production is the use of laser radiation. At the same time, from the economic point of view, laser technologies used in livestock industry in the early period of ontogenesis for the realization of genetically inherent productive qualities are the most effective. The efficiency of the laser beam is manifested primarily in the multiple strengthening of the immune system, influencing the increase in animal productivity (Balkova et al., 2003; Perazzi et al., 2015). In this case, the effectiveness of laser beam on the area of biologically active points responsible for the innervation of the thymus manifests itself, first of all, in mobilization of immune system, which contributes to the activation of the protective forces of the animal's organism (Karu TI., 1987; Hernandez et al., 2010).

However, in sheep breeding, the mechanism of high biological activity of low-intensity laser radiation has been little studied. Therefore, some interest in the scientific plan is the mechanism of impact of low-frequency laser radiation on acupuncture points of young sheep that can influence in the formation of meat productivity and resistance. Among the methods that enable the objective evaluation of interior qualities and allowing to judge the state of organism's health, the more significant place is given to the study of blood. Therefore, biochemical blood parameters are increasingly being used to assess the economically useful characteristics of animals. The study of protein, lipid and carbohydrate metabolism, the level of resistance in postembryonic period of development of lambs, in our opinion, will help to reveal features of metabolism in sheep with impact of low-intensity laser radiation.

Copyright (C) 2017 The Authors. Published by Aleksandras Stulginskis University. This is an open-access article distributed under the terms of the Creative Commons Attribution License (CC-BY 4.0), which permits unrestricted use, distribution, and reproduction in any medium, provided the original author and source are credited. 


\section{MATERIAL AND METHODS}

The research was carried out in the territory of Stavropol region (the western part) under the conditions of the IV agroclimatic zone characterized by a moderately humid climate. The object of the study was the young sheep of three groups, each with 10 heads: group I - single irradiation at 2 months of age; group II - double irradiation with an interval of one month ( 2 and 3 months); group III - control, without the use of irradiation. The impact of low-intensity laser radiation was performed on the nervous center located in the region of the first thoracic vertebra and responsible for the innervation of thymus, irritation of which activation of function of the thymus, which plays an important role in the formation of animal immunity. The duration of exposure to the area was one minute. In our work, we used the apparatus of «STP» brand of low-intensity laser radiation from the near infrared spectrum. Sampling of blood for laboratory tests was carried out from the jugular vein in the morning hours before feeding. The resistance indicators (bactericidal, lysozyme activity of blood serum, phagocytic alctivity of leukocytes) were determined using the methodological recommendations of All-Russian Research Institute of Sheep and Goat Breeding. Biochemical studies, including determination of the level of total protein, were determined by the refractometric method, the fractional composition by the colorimetric method; the activity of transamination enzymes is aspartate aminotransferase (AST), alanine aminotransferase (ALT) - were determined using the set of reactants "LAHEMA"; the glucose level was established using the set of reactants "Glucose-FKD"; calcium was determined by the complexometric method, phosphorus in reaction with molybdenum-acidic ammonium.

\section{RESULTS AND DISCUSSION}

The comparative analysis of live weight in the experimental animals, both during the formation of lambs in groups at the time of birth and at 2 months of age, didn't reveal significant differences in the studied trait. However, from the age of 3 months after treatment with low-intensity laser radiation, there are observed superiority in size of live weight of lambs of I and II experienced groups (4.0; $4.6 \%$ ) over control. In the subsequent age periods, the revealed differences between the experimental and control groups of animals by size of the live weight are increased and amount to 4.5 months 12.4; $14.6 \%$; In 6.5 months: $12.5 ; 14.7 \%$ (Table 1 ). The revealed regularity of advantages of experimental animals in size of the live weight was also preserved in terms of the average daily gain. Thus, the lambs of I and II groups had the highest growth energy, exceeding the young growth of the control group from 3 to 4.5 months by 8.7 and $18.6 \%$, in the period from 4.5 to 6.5 months: by 13.0 and $15.3 \%$.

Table 1. Productive indicators of sheep at influence of low-intensity laser radiation

\begin{tabular}{|c|c|c|c|}
\hline \multirow{2}{*}{ Indicator } & \multicolumn{3}{|c|}{ Group of animals } \\
\cline { 2 - 4 } & I experimental & II experimental & III control \\
\hline Live weight in 3 months, $\mathrm{kg}$ & $24.15 \pm 0.60$ & $24.30 \pm 0.50$ & $23.24 \pm 0.40$ \\
\hline Live weight in 4.5 months, $\mathrm{kg}$ & $30.00 \pm 0.90$ & $30.60 \pm 0.60$ & $26.70 \pm 0.50$ \\
\hline Dead weight, $\mathrm{kg}$ & $17.30 \pm 1.00$ & $18.10 \pm 0.80$ & $15.10 \pm 1.10$ \\
\hline Dressed weight, \% & 46.10 & 47.20 & 45.20 \\
\hline
\end{tabular}

The results of the control slaughter indicate that a large amount of dead weight was characteristic for the carcasses of young animals of I and II groups, which is 14.6 and $19.8 \%$ higher than peers of the control group. The revealed regularity in the animals of the experimental groups ensured a large amount of dressed weight, 0.9 and $2.0 \%$ higher than the indicators of young growth of the control group.

Consideration of productive qualities of animals suggests a positive influence of laser irradiation on the growth and development of the young sheep of the experimental groups, as evidenced by the greater size of the live weight, by the higher energy of growth in all studied periods of ontogenetic development, and the increase in meat productivity.

The identified changes during the period of observation in size of the live weight, the increments in the experimental animals are mainly quantitative nature. However, the basis of development of organism are not only quantitative, but also qualitative characteristics (the level of metabolites in the blood, the activity of natural resistance, etc.), which ultimately determines the productivity of animals. Therefore, we studied protein metabolism, indices of the concentrations of some metabolites of lipid, carbohydrate, mineral metabolism, indices characterizing protective potential at sheep at impact of low-intensity laser radiation.

The analysis of the obtained data testifies to the generality of the quantitative changes in the serum protein and its fractions at the experimental animals, which was reduced to increase of the numerical values of these parameters with age. However, the degree of increase of the studied parameters, in our opinion, was depended on influence of low-intensity laser radiation. The concentration of total protein in the serum of blood of experimental lambs was significantly higher in comparison with animals of the control group and it was: at the age of 2 months: $3.7-6.5 \%, 3$ months: $6.5-10.8 \%, 4.5$ months: $7.2-11.4 \%$ (Table 2).

The ontogenetic characteristics of the qualitative composition of the protein, its frac- tions in the experimental animals, were correlated with the fact that the lowest concentration of both albumins and globulins was observed in the early stages of postnatal ontogenesis. At the same time, at the age of 2 months in the blood of the sheep of the experimantal groups, no significant differences in levels of albumin were established. However, in the blood of the lambs of the experimental groups, a large concentration of globulins was detected at 8.0-10.0\%, exceeding the content of the studied 
biochemical parameter in the blood of the lambs of the control group. In the subsequent age periods, the level of metabolites of protein metabolism increased in animals of all groups. Thus a clear advantage on the concentration of both albumin and globulin fractions, lambs of the experimental groups were identified, which at the age of 3 months was 4.2-8.4\%; 8.6-13.0 \% , 4.5 months - 4.2-8.9\%; 9.8-13.6\%. With regard the subfractions of globulin, in all the periods of observations in the blood of the lambs of the experimental groups a high level of $\gamma$-globulins is established, increasing to 4.5 months of age.

As a result of researches at the animals of all the experimental groups, a decrease in the ratio of albumin-globulin coefficient with age was established.

The certain interest represents identification of the differences in transaminase activity of the blood in sheep at influence of low-intensity laser radiation, the concentration of which reflects the level of protein metabolism in organism of animals.

The general regularity is revealed, which indicates the highest level of activity of transaminases in serum of blood of the experimental animals, which, possibly, influenced the intensification of the reamination processes in their organism. The analysis of the obtained data revealed that the animals of the experimental groups have an increase in the level of activity of the enzymes of reamination with age, reaching a maximum in 4.5 months. Thus, the activity of the transamination enzymes in the blood of the lambs of the experimental groups in comparison with the lambs of the control group was: at the age of 2 months, according to ALT: 23.0-27.8\%; according to AST: $0.13-0.18$ mcg $\mathrm{l}^{-1} ; 3$ months according to ALT: $21.1-28.2 \%$, according to AST: $0.11-0.24 \mu \mathrm{kat} \mathrm{l}^{-1}$.

Table 2. Changes in biochemical parameters of blood in sheep at influence of low-intensity laser radiation

\begin{tabular}{|c|c|c|c|c|}
\hline \multirow{2}{*}{ Indicator } & \multirow{2}{*}{$\begin{array}{c}\text { Age periods, } \\
\text { month }\end{array}$} & \multicolumn{3}{|c|}{ Group of animals } \\
\hline & & I-experimental & II- experimental & III-control \\
\hline \multirow{3}{*}{ Total protein, $\mathrm{g} \mathrm{l}^{-1}$} & 2 & $70.50 \pm 0.30$ & $72.40 \pm 0.40$ & $68.00 \pm 0.20$ \\
\hline & 3 & $75.00 \pm 0.50$ & $78.00 \pm 0.09$ & $70.40 \pm 0.40$ \\
\hline & 4.5 & $76.30 \pm 0.50$ & $79.30 \pm 0.20$ & $71.20 \pm 0.30$ \\
\hline \multirow{3}{*}{ Albumins, $\mathrm{g} \mathrm{l}^{-1}$} & 2 & $33.80 \pm 0.20$ & $33.90 \pm 0.34$ & $32.90 \pm 0.23$ \\
\hline & 3 & $34.80 \pm 0.50$ & $36.20 \pm 0.20$ & $33.40 \pm 0.50$ \\
\hline & 4.5 & $35.00 \pm 0.44$ & $36.60 \pm 0.30$ & $33.60 \pm 0.50$ \\
\hline \multirow{3}{*}{ Globulins, $\mathrm{g} \mathrm{l}^{-1}$} & 2 & $37.80 \pm 0.20$ & $38.50 \pm 0.50$ & $35.00 \pm 0.40$ \\
\hline & 3 & $40.20 \pm 0.70$ & $41.80 \pm 0.24$ & $37.00 \pm 0.70$ \\
\hline & 4.5 & $41.30 \pm 0.50$ & $42.70 \pm 0.33$ & $37.60 \pm 0.60$ \\
\hline \multirow{3}{*}{$\alpha$-globulins, g/l } & 2 & $12.00 \pm 0.30$ & $12.20 \pm 0.21$ & $11.50 \pm 0.30$ \\
\hline & 3 & $12.20 \pm 0.50$ & $13.10 \pm 0.32$ & $12.00 \pm 0.22$ \\
\hline & 4.5 & $12.50 \pm 0.20$ & $13.10 \pm 0.50$ & $12.00 \pm 0.22$ \\
\hline \multirow{3}{*}{$\beta$-globulins, $\mathrm{g} \mathrm{l}^{-1}$} & 2 & $7.80 \pm 0.20$ & $8.20 \pm 0.20$ & $7.70 \pm 0.24$ \\
\hline & 3 & $8.30 \pm 0.30$ & $8.60 \pm 0.30$ & $8.00 \pm 0.01$ \\
\hline & 4.5 & $8.70 \pm 0.10$ & $8.80 \pm 0.04$ & $8.00 \pm 0.01$ \\
\hline \multirow{3}{*}{$\gamma$-globulins, $\mathrm{g} \mathrm{l}^{-1}$} & 2 & $18.00 \pm 0.10$ & $18.10 \pm 0.10$ & $15.80 \pm 0.30$ \\
\hline & 3 & $19.70 \pm 0.30$ & $20.10 \pm 0.20$ & $17.00 \pm 0.40$ \\
\hline & 4.5 & $20.10 \pm 0.50$ & $20.80 \pm 0.30$ & $17.60 \pm 0.40$ \\
\hline \multirow{3}{*}{$\begin{array}{l}\text { Coefficient of the ratio of } \\
\text { albumins to globulins }\end{array}$} & 2 & 0.87 & 0.88 & 0.94 \\
\hline & 3 & 0.87 & 0.87 & 0.91 \\
\hline & 4.5 & 0.84 & 0.86 & 0.89 \\
\hline \multirow{3}{*}{$\begin{array}{l}\text { Aspartate aminotransferase } \\
\qquad(\mathrm{AST}), \mu \text { kat } 1^{-1}\end{array}$} & 2 & $0.33 \pm 0.06$ & $0.38 \pm 0.03$ & $0.20 \pm 0.06$ \\
\hline & 3 & $0.46 \pm 0.03$ & $0.59 \pm 0.06$ & $0.35 \pm 0.04$ \\
\hline & 4.5 & $0.73 \pm 0.03$ & $0.78 \pm 0.05$ & $0.37 \pm 0.10$ \\
\hline \multirow{3}{*}{$\begin{array}{l}\text { Alanine aminotransferase } \\
\text { (ALT), } \mu{\text { kat } l^{-1}}^{-1}\end{array}$} & 2 & $0.75 \pm 0.10$ & $0.78 \pm 0.08$ & $0.61 \pm 0.07$ \\
\hline & 3 & $0.86 \pm 0.06$ & $0.91 \pm 0.10$ & $0.71 \pm 0.05$ \\
\hline & 4.5 & $0.79 \pm 0.08$ & $1.05 \pm 0.05$ & $0.34 \pm 0.04$ \\
\hline \multirow{3}{*}{ Glucose level, $\mathrm{mol} \mathrm{l}^{-1}$} & 2 & $3.20 \pm 0.10$ & $3.40 \pm 0.10$ & $2.80 \pm 0.20$ \\
\hline & 3 & $3.30 \pm 0.10$ & $3.40 \pm 0.20$ & $3.00 \pm 0.40$ \\
\hline & 4.5 & $3.40 \pm 0.20$ & $3.60 \pm 0.40$ & $3.30 \pm 0.30$ \\
\hline \multirow{3}{*}{$\begin{array}{l}\text { Lipoproteins of low density, } \\
\qquad \mathrm{g} \mathrm{l}^{-1}\end{array}$} & 2 & $0.60 \pm 0.30$ & $0.70 \pm 0.10$ & $0.50 \pm 0.10$ \\
\hline & 3 & $0.60 \pm 0.20$ & $0.80 \pm 0.10$ & $0.50 \pm 0.20$ \\
\hline & 4.5 & $0.80 \pm 0.20$ & $1.10 \pm 0.30$ & $0.60 \pm 0.20$ \\
\hline \multirow{3}{*}{$\begin{array}{l}\text { The amount of } \\
\text { calcium, mg }\end{array}$} & 2 & $5.00 \pm 0.10$ & $5.60 \pm 0.20$ & $4.70 \pm 0.20$ \\
\hline & 3 & $1.00 \pm 0.30$ & $1.10 \pm 0.10$ & $0.20 \pm 0.10$ \\
\hline & 4.5 & $14.70 \pm 0.10$ & $15.70 \pm 0.30$ & $12.00 \pm 0.20$ \\
\hline \multirow{3}{*}{ Amount of phosphorus, mg } & 2 & $5.50 \pm 0.20$ & $6.40 \pm 0.30$ & $3.90 \pm 0.30$ \\
\hline & 3 & $8.70 \pm 0.30$ & $9.80 \pm 0.30$ & $4.60 \pm 0.50$ \\
\hline & 4.5 & $3.80 \pm 0.30$ & $4.10 \pm 0.20$ & $2.70 \pm 0.10$ \\
\hline
\end{tabular}

Thus, summing up the comparative study of the age dynamics of metabolites of protein metabolism in sheep at influence of low-intensity laser radiation established that the nature of the changes in the content of total protein and its fractional composition is uniform for all animals in all periods of ontogenesis. It was to an increase of the level of serum 
protein with age, an increase in globulin fraction and a slight increase in albumin. However, the lambs irradiated twice in the thymus region were distinguished by their superiority of the level of total protein, their amount of albumins and globulins during all the periods of observation. In addition, an increase of the level of $\gamma$-globulins in the serum of blood of the lambs of this group indicates a higher protective potential of their organism to development of antibodies.

The obtained data revealed the common ontogenetic regularity for all the experimantal animals that consists in the fact that the level of activity of the transamination enzymes underwent significant changes: there an increase in the activity of transinaminases by 3 months of age and a gradual decrease in the subsequent aging periods are established at animals of the control group; the level of activity of transamination enzymes is increased with age reaching a maximum of 4.5 months at the experimental animals.

Among the experimental groups of lambs, the young animals with double irradiation in the area of thymus were characterized by the best indicators reflecting the level of protein metabolism in organism of animals.

Since we have the observed patterns that occurred in the composition of blood, its protein spectrum of the experimental animals are reliable, we considered that it is necessary to study the indices of the concentrations of some metabolites of lipid and carbohydrate metabolism in the blood of lambs at influence of low-intensity laser radiation. With their help we tried to compare the tension of energy exchange in the organism of young sheep under the influence of laser puncture.

Our results indicate that the level of components of lipid metabolism (low-density lipoproteins) underwent certain changes in the organism of the lambs of the experimental groups. It was established that there is an increase occurs in the content of low-density lipoproteins, reaching a maximum of 4.5 months, with age in experimental animals. Thus, in blood of the lambs of I and II groups, the concentration of low-density lipoproteins has increased by $0.20-0.30 \mathrm{~g} \mathrm{l}^{-1}$.

The data are not less contrasting that obtained by studying of effect of low-intensity laser radiation on the components of carbon exchange. It was revealed that the level of glucose, which characterizes the intensity of energy metabolism, has also undergone quantitative changes. The general pattern has been established, it indicating that with age, there is an insignificant increase in the level of glucose in blood of all animals. However, the high concentration of the studied component in all age periods is observed in the blood of the lambs of the experimental groups in comparison with the lambs of the control group: at the age of 2 months: 14.3-21.4\%; 3 months: 10.0-13.3\%; 4.5 months: 3.0-9.0\%.

The revealed regularity between the experimental and control groups of animals is characteristic also for the indicators of the mineral metabolism. The results of our studies indicate that the level of the components of the mineral metabolism has also undergone certain changes, both in the experimental groups of animals and in the control group of lambs in various stages of postnatal ontogenesis. Thus, at the age of 2 months, the concentration of calcium and phosphorus in the blood of lambs of all groups varied within 4.7-5.6 mg $100 \mathrm{~g}^{-1}$ and 3.9-6.4 mg $100 \mathrm{~g}^{-1}$. From the age of 3 months in blood of all groups of animals, the calcium level decreased by $4.0-4.5 \mathrm{mg} 100 \mathrm{~g}^{-1}$, but the phosphorus content increased by $0.4-3.4 \mathrm{mg} 100 \mathrm{~g}^{-1}$. However, when lambs reached 4.5 months of age, the highest concentration of calcium

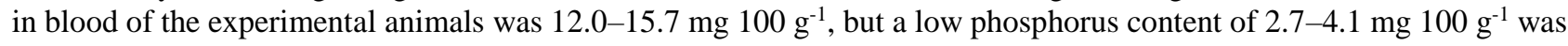
observed. In all periods of ontogenesis, the concentration of calcium and phosphorus in the blood of the lambs of the experimental groups was higher than in the blood of the animals of the control group and it was: at the age of 2 months: 6.4-19.1\%; 28.9-39.1\%, 4.5 months: $22.5-30.8 \%$; 29.1-39.0\%.

The conducted researches revealed certain differences, which appeared in the features of carbohydrate, lipid, mineral metabolism. At the same time, a high concentration of metabolic energy (low-density lipoproteins, glucose), mineral metabolism (calcium, phosphorus) was established in the blood of the experimental animals in the examined stages of postnatal ontogenesis than in the blood of the animals of the control group. Taking into account the revealed regularity, it is possible to assume that the lambs under the influence of low-intensity laser radiation use most actively the energy-related blood for biosynthetic processes during the period of its growth and development. Among the experimental groups of lambs, the best indicators characterizing the intensity of the energy exchange were lambs with double irradiation in the area of thymus.

Table 3. The level of natural resistance of sheep at influence of low-intensity laser radiation, $\%$

\begin{tabular}{|c|c|c|c|c|}
\hline \multirow{2}{*}{ Indicator } & $\begin{array}{c}\text { Age periods, } \\
\text { months }\end{array}$ & I experimental & II experimental & III control \\
\cline { 2 - 5 } & 2 & $27.80 \pm 4,30$ & $28.00 \pm 3,90$ & $23.50 \pm 4,80$ \\
\cline { 2 - 5 } $\begin{array}{c}\text { The lysozyme } \\
\text { activity of } \\
\text { serum of blood }\end{array}$ & 3 & $40.40 \pm 3.60$ & $43.80 \pm 4.00$ & $24.40 \pm 5.90$ \\
\cline { 2 - 5 } & 4.5 & $33.80 \pm 3,30$ & $42.50 \pm 4.50$ & $27.50 \pm 3.90$ \\
\hline $\begin{array}{c}\text { The bactericidal } \\
\text { activity of } \\
\text { serum of blood }\end{array}$ & 2 & $38.80 \pm 4.00$ & $39.10 \pm 4,30$ & $33.70 \pm 3.90$ \\
\cline { 2 - 5 } & 3 & $40.40 \pm 3.60$ & $43.80 \pm 4.00$ & $35.50 \pm 4.50$ \\
\hline $\begin{array}{c}\text { The phagocytic } \\
\text { activity of } \\
\text { leukocytes }\end{array}$ & 4.5 & $24.40 \pm 5.20$ & $52.70 \pm 4.50$ & $22.00 \pm 1.00$ \\
\cline { 2 - 5 } & 2 & $37.40 \pm 1.20$ & $30.60 \pm 1.40$ & $23.60 \pm 1.20$ \\
\hline
\end{tabular}

The evaluation of the protective potential of the experimental animals revealed a number of features that are due not only to maturity of organism at various stages of ontogenesis, but, in our opinion, to the specific influence of laser puncture. The generality of the age-related changes of the indices of natural resistance in the experimental animals revealed a significant superiority of the young animals of the experimental groups over the animals of the control group according to the level of activity of both humoral and cellular factors of reactivity. So, in all periods of observation, the 
parameters of cellular immunity (phagocytic activity of leukocytes) of the experimental animals were higher at the age of 2 months: by $5.6-8.6 \%$, in 3 months: by $13.8-18.4 \%$, in 4.5 months: by $15.5-21.7 \%$ than at the lambs of the control group. Humoral factors (bactericidal, lysozyme activity of blood serum) in the blood of young sheep of the experimental groups increased at the age of 2 months by 5.1-5.4 and 4.3-4.5\%, in 3 months: by 4.9-8.3 and 16.0-19.4 \%, in 4.5 months: by $6.8-15.1$ and $6.3-15.0 \%$ in comparison with the level of resistance of the animals of the control group (Table 3).

In all periods of postnatal ontogenesis, the advantage of the protective potential of the organism of the young sheep of the experimental groups irradiated in the region of the thymus is revealed. It should be noted that the amplitude of the revealed changes didn't exceed the limits of the physiological norm. Among the experimental groups of lambs, the youngest sheep irradiated twice in the thymus region were characterized by the best protective potential.

\section{CONCLUSION}

Summarizing the obtained results, it is possible to make the conclusion that the impact of laser irradiation on the organism of sheep (once and twice in the thymus region) activates to biochemical processes better and mechanisms of natural resistance that ensuring their intensive growth and development. The developed method of laser puncture (single and double irradiation in the thymus region) can be used to enhance the meat productivity, safety and resistance of sheep.

\section{REFERENCES}

1. Hernandez, A.C., Dominguez, P.A., Cruz, O.A., Ivanov, R., Carballo, C.A., Zepeda, B.R. 2010. Laser in agriculture. International Agrophysics, Vol. 24, pp. 407-422.

2. Nikitenko, E.V., Shumayenko, S.N., Skorykh, L.N., Kovalenko, D.V. 2016. The effect of laser puncture on the natural resistance of young sheep in postnatal ontogenesis. Modern trends in the development of science and technology, Vol. 7, No. 1.pp. 42-44.

3. Perazzi, A., Patruno, M., Martinello, T., Glazar, M., Iacopetti, I. 2015. Effect of MLS Laser Therapy for the treatment of experimentally induced acute tendinopathy in sheep - a preliminary study. Energy for Health, Vol. 14, pp. 4-7.

4. Karu, T.I. 1987. Photobiological Fundamentals of LowPower Laser Therapy. IEEE Journal of Quantum Electronics, Vol. 23, Iss. 10, pp. 1703-1717. https://doi.org/10.1109/JQE.1987.1073236

5. Balkova, I.I., Inozemtsev V.P., Stravsky, Ya.S., Khristoforov, V.N. 2003 Laser radiation as a factor in increasing non-specific resistance of animals (Laser radiation as a factor to increase the nonspecific resistance of animals). Quantum Therapy in Veterinary Medicine, 2003, p. 11. [In Russian] 